Original Research Paper

\title{
Associations between Farmer Demographics, Management Practices and Attitudes towards Bovine Viral Diarrhoea and its Control
}

\author{
${ }^{1}$ Sasha Renee Lanyon, ${ }^{2}$ Malcolm Anderson and ${ }^{1,3}$ Michael Phillip Reichel \\ ${ }^{1}$ School of Animal and Veterinary Sciences, University of Adelaide, Roseworthy, Australia \\ ${ }^{2}$ Animal Health, Biosecurity SA, Nuriootpa, Australia \\ ${ }^{3}$ School of Veterinary Medicine, City University of Hong Kong, Hong Kong
}

Article history

Received: 11-06-2016

Revised: 30-06-2017

Accepted: 24-10-2017

Corresponding Author:

Sasha Renee Lanyon

School of Animal and

Veterinary Sciences, University of Adelaide, Roseworthy,

Australia

Email: sasha.lanyon@adelaide.edu.au

\begin{abstract}
Farmer participation is crucial to the successful mitigation of Bovine Viral Diarrhoea (BVD) associated losses. This study aimed to identify producer groups most likely to benefit from BVD education by assessing the relationships between demographic and management variables, biosecurity behaviours and BVD awareness. A postal survey of South Australian cattle farmers was conducted, with 631 responses received and analysed. The survey tested attitudes and interests towards and perceived and demonstrable knowledge of BVD. Increases in the respondents' perceived understanding, knowledge and interest scores were observed when Pestigard ${ }^{\circledR}$ was routinely used and when Pestivirus testing had been conducted in the herd. Perceived understanding and knowledge scores were also increased when quarantine procedures are in place, when the producer had attended a BVD seminar or educational session, or was aware of the Bovine Johnes Disease Market Assurance Program. Regular use of either 5 in 1 or 7 in 1 vaccinations was associated with increased knowledge of BVDV, while health and vaccination status checks prior to introduction of new cattle are associated with increased perceived understanding of BVDV. This study revealed that uptake of positive biosecurity and BVDV specific behaviours was associated with perceived understanding, knowledge and interest in BVDV and supports the need for excellent education and awarenessraising programs in association with systematic control or eradication schemes. Improvements in knowledge of BVD could be related to improvements in other areas of animal health and biosecurity.
\end{abstract}

Keywords: Survey, Awareness, South Australia, BVD, Bovine Viral Diarrhoea, Pestivirus

\section{Introduction}

Bovine Viral Diarrhoea (BVD), caused by a Pestivirus of the family Flaviviridae, has a significant financial impact in infected cattle populations. Structured control programs, generally based on a test and cull approach, have been shown to be highly effective and economically beneficial (Häsler et al., 2012; Valle et al., 2000). Stakeholder awareness is acknowledged as a primary factor crucial to the success of control and mitigation schemes (Barrett et al., 2011;
Lindberg and Alenius, 1999). As such, control schemes, including those in Switzerland (Presi et al., 2011) and various American states (Ridpath, 2012), have often incorporated an educational component. An understanding of the relationships between demographic and management factors and farmer awareness of BVD may allow identification of producer groups that are most likely to benefit from educational programs, such as those that have the poorest awareness of BVD and implement the fewest biosecurity procedures. In turn, this may allow 
education schemes to be effectively targeted to those producers ensuring the greatest positive impact and improving the likelihood of producer support of BVD control efforts. Therefore, this study aimed to assess the relationships between demographic and management factors, biosecurity behaviours and knowledge of, perceived understanding of and interest in BVD and its control.

\section{Materials and Methods}

\section{Survey}

As previously reported (Lanyon et al., 2015), a 4page questionnaire was mailed to all $(\mathrm{n}=4,165)$, South Australian cattle farmers registered in the Primary Industries Information Management System (PIIMS) database as managing a herd of 35 or more head of cattle. Farmers managing herds of fewer than 35 animals were excluded in an attempt to focus on commercial producers (and hence exclude part-time or hobby farmers). A total of 631 responses were received (response rate $15.2 \%$ ). Response bias in this survey has been extensively discussed (Lanyon et al., 2015). Due to the relatively low response rate, the results presented in this manuscript are interpreted within the confines of the respondent population without extrapolation.

\section{Statistical Analysis}

A perceived understanding score and an interest score were calculated for each respondent as previously reported (Lanyon et al., 2015), with a high score (on a scale of 1 to 7) representative of high self-perceived understanding of BVD or high interest in BVD, respectively. Similarly, a knowledge score was calculated on a scale of -16 to 16 (Lanyon et al., 2015), with a high score indicative of high demonstrated knowledge of BVD.

Simple linear regressions were performed in statistical package $\mathrm{R}$ Version 3.1.2 using the $\operatorname{lm}($ ) function to assess which of twenty-one explanatory variables (Table 1) were significantly associated with the dependent variables: Perceived understanding score, knowledge score and interest score variables. All explanatory variables included in the analysis had $<10 \%$ missing responses. For each dependent variable, multiple linear regression was also performed in R Version 3.1.2 using the $\operatorname{lm}($ ) function. The starting model consisted of the main effects of each explanatory variable that simple linear regression showed to be significantly $(\mathrm{p}<0.05)$ associated with that dependent variable. Backwards stepwise elimination was performed using Akaike Information Criteria (AIC) and t-values as elimination criteria, until only significant variables remained.

Table 1:Explanatory variables from a postal questionnaire survey of 631 South Australian cattle farmers. All variables have $<10 \%$ missingness

\begin{tabular}{|c|c|c|}
\hline Variable name & Question & Answer options \\
\hline Adequate vaccination & $\begin{array}{l}\text { How often do you administer } \\
{[5 \text { in } 1 \text { or } 7 \text { in } 1 \text { vaccine] to your cattle? }}\end{array}$ & $\begin{array}{l}\text { 'Never' or 'single dose as calves' recorded as 'NO'. } \\
\text { 'double dose as calves' or 'annually for life' recorded as 'Yes'. }\end{array}$ \\
\hline Ag related occupation & Primary occupation & $\begin{array}{l}\text { Free text. 'Agriculture related', as designated by authors, recorded } \\
\text { 'YES'. 'Agriculture related' included farmer, grazier, livestock } \\
\text { transport, fencing contractor and stock agent. 'Not agriculture } \\
\text { related', including teacher, doctor or tradesman was recorded 'No'. }\end{array}$ \\
\hline Age & Age & Recorded in years \\
\hline Beef/Dairy & $\begin{array}{l}\text { Are you involved in: Dairy/Beef? } \\
\text { (Circle all that apply.) }\end{array}$ & $\begin{array}{l}\text { Circled 'dairy' recorded as 'dairy'. } \\
\text { Circled 'beef' recorded as 'beef'. } \\
\text { Circled both 'beef' and 'dairy' recorded as 'both'. }\end{array}$ \\
\hline Breeds & What breed(s) of cattle? & $\begin{array}{l}\text { 'ANGUS', } \\
\text { Holstein/Friesian/Holstein Friesian recorded as 'FRIESIAN', } \\
\text { '(Poll) Hereford', } \\
\text { 'Murray grey', } \\
\text { 'Santa GERTRUDIS', } \\
\text { '(Poll) shorthorn', } \\
\text { 'Other British Beef Breed', } \\
\text { 'European beef breed', } \\
\text { 'Other dairy breed', } \\
\text { 'Mixed or cross beef breeds', } \\
\text { 'Mixed or Cross Beef Breeds including angus blood', } \\
\text { 'Mixed or cross dairy breeds'. }\end{array}$ \\
\hline BVD seminar & $\begin{array}{l}\text { Have you ever attended an educational } \\
\text { session about or related to BVD? }\end{array}$ & 'YES' or 'NO' \\
\hline BVD testing & $\begin{array}{l}\text { Do you test cattle for bovine } \\
\text { viral diarrhoea (Pestivirus)? }\end{array}$ & 'YES' or 'NO' \\
\hline
\end{tabular}


Table 1: Continue

Commercial breeder

Decision maker

Disease report level

Education

Education

.

cos

\author{
'YES' or 'NO'. \\ 'YES', 'Part responsibility' or 'NO' \\ 'Some', '5' or ' $10 \%$ ' \\ 'Primary school', \\ 'Year 10 or equivalent', \\ 'Completed year 10, continued at school but did not complete \\ year 12', \\ 'Year 12 or equivalent', \\ 'Post-school qualification-not ag related', \\ 'Bachelor degree-not Ag related', \\ 'Post-school qualification or bachelor degree-Ag related', \\ 'Post-graduate degree' \\ 'Male' or 'Female' \\ Numeric \\ 'Unaware', \\ 'Aware and involved', \\ 'Aware and uninvolved', \\ 'Aware and previously but not currently involved' \\ 'Never' recorded as 'NO' \\ 'Single dose as calves', 'double dose as calves', \\ 'Annually for life' or 'before introduction' recorded as 'Yes' \\ 'Yes' or 'No'.
}

'Vet', 'PIRSA', 'Vet and PIRSA' or 'other'

'Cattle Owner', 'Manager', 'Farm worker' or 'other'

'YES' or 'NO'

'Yes' or 'No'

Recorded in years

\section{Results}

Overall, eight explanatory variables (of twenty-two included the analysis) were retained in the final multiple linear regression model for at least one dependent variable. Table 2-4 show the parameter estimates, standard errors and probabilities for each retained explanatory variable in the models for perceived understanding score, knowledge score and interest score, respectively.

The use of Pestigard ${ }^{\circledR}$ in the herd and any BVD testing of cattle was significantly associated $(p<0.004)$ with increases in the respondents' perceived understanding, knowledge and interest scores. Attendance at a BVD seminar and (self-reported) implementation of quarantine procedures on farm were significantly associated with increases in perceived understanding and knowledge, but not interest scores. By contrast, respondents that were unaware of the Johne's Cattle Market Assurance Program that is active in South Australia, had significantly lower perceived understanding and knowledge scores than their counterparts that were aware of the program but not involved (the reference group). Interestingly, those respondents that were actively involved in the program had significantly lower perceived understanding (but not knowledge) scores than the reference group. Perceived understanding scores were also significantly associated with gender, with male respondents likely to score lower and with implementation of vaccination and health procedures when introducing stock associated with higher scores. In addition, knowledge scores were significantly positively associated with adequate routine vaccination against clostridial diseases, using either 5 in 1 or 7 in 1 vaccines. 
Table 2: Parameter estimates, standard errors, and probabilities of significant explanatory variables in multiple regression analysis of farmer's perceived understanding of the disease Bovine viral diarrhoea as measured by composite 'perceived understanding score' (possible values ranging from 1 (low perceived understanding) to 7 (high perceived understanding). Parameter estimates indicate the change in perceived understanding score associated with the category, relative to the reference category

\begin{tabular}{|c|c|c|c|c|}
\hline Variable & Category & Paran & Standard error & $\mathrm{p}$-value \\
\hline Intercept & & 4.34 & 0.17 & $<0.001$ \\
\hline Gender & Female & & Reference & \\
\hline & Male & -0.59 & 0.14 & $<0.001$ \\
\hline Undertakes vaccination and & No & & Reference & \\
\hline & Yes & 0.41 & 0.11 & $<0.001$ \\
\hline Undertakes quarantine of $\mathrm{New}$ Stock & No & & Reference & \\
\hline & Yes & 0.24 & 0.1 & 0.019 \\
\hline Has attended BVD seminar & No & & Reference & \\
\hline & Yes & 0.64 & 0.13 & $<0.001$ \\
\hline Has ever undertaken any BVD testing & No & & Reference & \\
\hline & Yes & 0.57 & 0.16 & $<0.001$ \\
\hline Ever uses pestigard & No & & Reference & \\
\hline & Yes & 0.9 & 0.15 & $<0.001$ \\
\hline $\begin{array}{l}\text { Awareness of and involvement } \\
\text { in Johnes disease cattle MAP }\end{array}$ & $\begin{array}{l}\text { Aware of program but } \\
\text { not involved }\end{array}$ & & Reference & \\
\hline & $\begin{array}{l}\text { Aware of program and previously } \\
\text { but not currently involved }\end{array}$ & -0.08 & 0.24 & 0.727 \\
\hline & Involved in program & -0.39 & 0.15 & 0.01 \\
\hline & Unaware of program & -0.67 & 0.11 & $<0.001$ \\
\hline
\end{tabular}

Model statistics: Adjusted R-squared: 0.3543, F-statistic: 29.77 on 9 and 463 DF, p-value: $<2.2 \times 10^{-16}$

Table 3:Parameter estimates, standard errors, and probabilities of significant explanatory variables in multiple regression analysis of farmer's knowledge of the disease Bovine viral diarrhoea as measured by composite 'knowledge score' (possible values ranging from -16 (low knowledge) to +16 (high knowledge). Parameter estimates indicate the change in knowledge score associated with the category, relative to the reference category

\begin{tabular}{|c|c|c|c|c|}
\hline Variable & Category & Parameter estimate & Standard error & p-value \\
\hline Intercept & & 3.94 & 0.32 & $<0.001$ \\
\hline \multirow[t]{2}{*}{ Adequately vaccinates with 5 in 1 or 7 in 1} & No & & Reference & \\
\hline & Yes & 0.82 & 0.34 & 0.016 \\
\hline \multirow[t]{2}{*}{ Undertakes quarantine of New Stock } & No & & Reference & \\
\hline & Yes & 0.68 & 0.31 & 0.03 \\
\hline \multirow[t]{2}{*}{ Has attended BVD seminar } & No & & Reference & \\
\hline & Yes & 2.67 & 0.42 & $<0.001$ \\
\hline \multirow[t]{2}{*}{ Has ever undertaken Any BVD testing } & No & & Reference & \\
\hline & Yes & 2.2 & 0.51 & $<0.001$ \\
\hline \multirow[t]{2}{*}{ Ever uses pestigard } & No & & Reference & \\
\hline & Yes & 2.79 & 0.48 & $<0.001$ \\
\hline \multirow{4}{*}{$\begin{array}{l}\text { Awareness of and involvement in } \\
\text { Johnes disease cattle MAP }\end{array}$} & Aware of program but not involved & & Reference & \\
\hline & $\begin{array}{l}\text { Aware of program and previously } \\
\text { but not currently involved }\end{array}$ & -0.03 & 0.75 & 0.97 \\
\hline & Involved in program & -0.14 & 0.47 & 0.76 \\
\hline & Unaware of program & -1.54 & 0.35 & $<0.001$ \\
\hline
\end{tabular}

Model statistics: Adjusted R-squared: 0.3543, F-statistic: 29.77 on 9 and 463 DF, p-value: $<2.2 \times 10^{-16}$

Table 4: Parameter estimates, standard errors, and probabilities of significant explanatory variables in multiple regression analysis of farmer's interest in the disease Bovine viral diarrhoea as measured by composite 'interest score' (possible values ranging from 1 (low interest) to 7 (high interest). Parameter estimates indicate the change in interest score associated with the category, relative to the reference category

\begin{tabular}{lllll}
\hline Variable & Category & Parameter estimate & Standard error & p-value \\
\hline Intercept & & 4.9 & 0.07 & $<0.001$ \\
Ever undertaken any BVD testing & No & & Reference & 0.17 \\
& Yes & 0.51 & Reference & 0.003 \\
Ever uses pestigard & No & & 0.17 & $<0.001$ \\
& Yes & 0.77 & \\
\hline
\end{tabular}

Model statistics: Adjusted R-squared: 0.06892, F-statistic: 20.54 on 2 and 526 DF, p-value: $2.573 \times 10^{-16}$ 


\section{Discussion}

There are many factors that may influence a farmer's attitudes and decision making process, including the physical and economic constraints of the farm, the farmer's demographics, education, experience and stage of life, the farm succession plan (Toma et al., 2013). The present study is the first of this nature undertaken in Australia, examining associations between knowledge, understanding and interest in BVD with farmer demographics and farm management practices. The results of this study revealed significant associations between the dependent variables of perceived understanding, knowledge and interest in BVD and onfarm disease management behaviours including vaccination practices and quarantine habits. While direct comparison between Australian respondents and those in Britain and the US is difficult, similarities are certainly evident. For example, Sanderson et al. (2000) reported that US beef breeders that quarantined introduced stock were more likely to vaccinate their herds and require cattle to be vaccinated prior to introduction, suggesting that these producers may be driven by an underlying characteristic, potentially their understanding of disease risk and biosecurity. Sanderson et al. (2000) point out that the evaluation of biosecurity must not only focus on effectiveness and cost, but must relate to producerspecific factors such perception of risk, risk aversion and potential disease losses.

In a survey of British livestock veterinarians, Gunn et al. (2008) revealed that veterinarians viewed farmers as unwilling, unable or lacking the interest or time to invest in biosecurity. These publications support the results of the present survey that suggest that knowledge and understanding of disease is positively associated with biosecurity and disease control behaviours. These results suggest that increasing knowledge of biosecurity (or, BVDV, specifically) could increase the implementation of positive biosecurity behaviours.

A study by Gunn et al. (2008) showed that British farmers have mixed perceptions of biosecurity, with farmers positively associating with increases in profitability gained through improved health a welfare and considering biosecurity to be a matter of personal pride and their own responsibility so as to secure a future in farming. However, these same farmers also associated biosecurity with decreased freedom, increased bureaucracy and rules, costly and as unlikely to achieve the desired outcome without the cooperation of all stakeholders.

In general, the farmers in that British study expressed positive views on biosecurity when self-referential and negative views when considering externally imposed biosecurity requirements. In the present study, high knowledge and perceived understanding of BVD was observed to be associated with positive biosecurity actions. This suggests that, when well informed, respondents to this survey generally viewed biosecurity in a positive manner, resulting in positive action. This is supported by a similar finding of a very strong relationship between the knowledge and perceived importance of biosecurity and action observed by Toma et al. (2013) in another UK-based study. In that study, positive action was also associated with high perceived effects of disease outbreaks on farm profitability and perceived usefulness of information sources.

\section{Conclusion}

Schemes for the control of BVD through implementation of biosecurity rely on the commitment and cooperation of farmer populations. This study revealed that uptake of positive biosecurity and BVDV specific behaviours was associated with perceived understanding, knowledge and interest in BVDV supports the need for excellent education and awareness-raising programs in association with such projects. Improvements in knowledge of BVD could be related to improvements in other areas of animal health and biosecurity.

\section{Acknowledgement}

The authors thank all farmer respondents to the questionnaire for their time and willingness, the staff at PIRSA for compiling the returned questionnaire and IDEXX Laboratories Inc. for their support of the project.

\section{Funding Information}

The authors acknowledge IDEXX Laboratories Inc. for providing free herd profile testing as incentive to complete the questionnaire.

\section{Author's Contributions}

Sasha Renee Lanyon: Designed and coordinated the survey and questionnaire, completed data entry, management and analysis and drafted the manuscript.

Malcolm Anderson: Facilitated the survey mail-out and edited the manuscript.

Michael Phillip Reichel: Edited the questionnaire and edited the manuscript.

\section{Ethics}

This survey was approved by the University of Adelaide Human Research Ethics Committee (Project No: H-091-2011). 


\section{References}

Barrett, D.J., S.J. More, D.A. Graham, J. O'Flaherty and M.L. Doherty et al., 2011. Considerations on BVD eradication for the Irish livestock industry. Irish Veterinary J., 64: 1-10.

Gunn, G.J., C. Heffernan, M. Hall, A. McLeod and M. Hovi, 2008. Measuring and comparing constraints to improved biosecurity amongst GB farmers, veterinarians and the auxiliary industries. Preventive Veterinary Med., 84: 310-323. DOI: $10.1016 /$ j.prevetmed.2007.12.003

Häsler, B., K.S. Howe, P. Presi and K.D.C. Staerk, 2012. An economic model to evaluate the mitigation programme for bovine viral diarrhoea in Switzerland. Preventive Veterinary Med., 106: 162-173. DOI: 10.1016/j.prevetmed.2012.01.022

Lanyon, S.R., M.L. Anderson and M.P. Reichel, 2015. A survey of farmer attitudes to endemic disease management in South Australia, with a focus on Bovine Viral Diarrhoea (bovine pestivirus). Australian Veterinary J., 93: 157-163. DOI: 10.1111/avj.12316

Lindberg, A.L.E. and S. Alenius, 1999. Principles for eradication of Bovine Viral Diarrhoea Virus (BVDV) infections in cattle populations. Veterinary Microbiol., 64: 197-222. DOI: 10.1016/s0378-1135(98)00270-3
Presi, P., R. Struchen, T. Knight-Jones, S. Scholl and D. Heim. 2011. Bovine Viral Diarrhea (BVD) eradication in Switzerland-Experiences of the first two years. Preventive Veterinary Med., 99: 112-121. DOI: 10.1016/j.prevetmed.2011.01.012

Ridpath, J., 2012. Preventive strategy for BVDV infection in North America. Japanese J. Veterinary Res., 60: S41-S49. DOI: 10.14943/jjvr.60.suppl.s41

Sanderson, M.W., D.A. Dargatz and F.B. Garry, 2000. Biosecurity practices of beef cow-calf producers. J. Am. Veterinary Medical Association, 217: 185-189. DOI: 10.2460/javma.2000.217.185

Toma, L., A.W. Stott, C. Heffernan, S. Ringrose and G.J. Gunn, 2013. Determinants of biosecurity behaviour of British cattle and sheep farmers-A behavioural economics analysis. Preventive Veterinary Medicine, 108: 321-333. DOI: 10.1016/j.prevetmed.2012.11.009

Valle, P.S., E. Skjerve, S.W. Martin, R.B. Larssen and O. Osteras et al., 2000. A cost benefit evaluation of the Norwegian bovine virus diarrhoea control and eradication program. Proceedings of the 9th International Symposium on Veterinary Epidemiology and Economics, August, International Symposia on Veterinary Epidemiology and Economics, (VEE' 00), USA, pp: 511-513. 